\title{
Visualisasi Data Perhitungan SLA Pengiriman Unit Periode Januari-Desember 2021
}

\author{
Doni Andriansyah ${ }^{1}$
}

\begin{abstract}
Service Level Agreement (SLA) is a benchmark for the achievement of an activity carried out. one of the quality of service is the completion of work in accordance with the SLA. To be able to meet the needs of customer units in an area, the company cooperates with expedition vendors to be able to send units to destinations with a distance of more than $100 \mathrm{~km}$. Unit deliveries are also carried out internally by the company but with a distance of less than or only up to $100 \mathrm{~km}$. Monitoring needs to be done so that unit deliveries to customers arrive quickly, safely, and on time. Currently the process is done manually, namely the calculation of vendor and internal SLAs that still use Ms. Excel. The methods used in this research are Visual Data Mining (VDM) and Extract, Transfer, Load (ETL). The results of the research are in the form of a data visualization dashboard that can be used as monitoring the achievement of SLA unit delivery.
\end{abstract}

Intisari- Service Level Agreement (SLA) merupakan tolak ukur pencapaian atas suatu aktifitas yang dilakukan. salah satu kualitas pelayanan adalah penyelesaian pekerjaan yang sesuai dengan SLA. Untuk dapat memenuhi kebutuhan unit pelanggan disuatu daerah, perusahaan bekerja sama dengan vendor ekspedisi untuk dapat mengirimkan unit-unit ke tempat tujuan dengan jarak tempuh lebih dari $100 \mathrm{~km}$. Pengiriman unit juga dilakukan oleh internal perusahaan namun dengan jarak tempuh kurang dari atau hanya sampai 100 km. Perlu dilakukan monitoring agar pengiriman unit ke pelanggan tiba dengan cepat, aman, dan tepat waktu. Saat ini proses tersebut dilakukan secara manual, yaitu perhitungan SLA vendor dan internal yang masih menggunakan Ms. Excel. Metode yang digunakan dalam penelitian adalah Visual Data Mining (VDM) dan Extract, Transfer, Load (ETL). Hasil dari penelitian berupa dashboard visualisasi data yang dapat digunakan sebagai monitoring pencapaian SLA pengiriman unit.

Kata Kunci- Visualisasi Data, Mining, SLA, Monitoring

\section{PENDAHULUAN}

Service Level Agreement (SLA) merupakan tolak ukur pencapaian atas suatu aktifitas yang dilakukan, serta bagian dari perjanjian layanan secara keseluruhan antara dua entitas untuk peningkatan kinerja [1].

Dalam sebuah perusahaan, salah satu kualitas pelayanan adalah penyelesaian pekerjaan yang sesuai dengan SLA [2], hal ini untuk memberikan jaminan terhadap kepuasan pengguna sehingga mempengaruhi tingkat kepercayaan pengguna terhadap layanan yang diberikan.

Manajemen perusahaan memiliki peran penting dalam peningkatan kinerja untuk dapat mewujudkan tujuan yang akan

1 Jurusan Teknik Informatika, Universitas Nusa Mandiri, Jln. Kramat Raya No. 18 Jakarta Pusat 10450 INDONESIA 021-31908575 e-mail: doni.dad@nusamandiri.ac.id) dicapai melalui serangkaian kegiatan berupa perencanaan, pengorganisasian, pengarahan, dan pengendalian orang-orang serta sumber daya organisasi lainnya [1].

Untuk dapat memenuhi kebutuhan unit pelanggan disuatu daerah, perusahaan bekerja sama dengan vendor ekspedisi untuk dapat mengirimkan unit-unit ke tempat tujuan dengan jarak tempuh lebih dari $100 \mathrm{~km}$. Pengiriman unit juga dilakukan oleh internal perusahaan namun dengan jarak tempuh kurang dari atau hanya sampai $100 \mathrm{~km}$ saja. Sebagai bentuk jaminan atas kerja sama vendor dengan perusahaan, maka vendor memberikan SLA pengiriman unit berdasarkan daerah asal sampai dengan tujuan pengiriman. Pengiriman yang dilakukan oleh internal perusahaan ditetapkan hanya 1 hari.

Perlu dilakukan monitoring agar pengiriman unit ke pelanggan tiba dengan cepat, aman, dan tepat waktu. Saat ini proses tersebut dilakukan secara manual, yaitu perhitungan SLA vendor dan internal yang masih menggunakan Ms. Excel.

Dari permasalahan yang terungkap diatas maka diperlukanlah sebuah dashboard yang dapat memvisualisasikan hasil perhitungan SLA pengiriman oleh vendor atau internal dengan target tanggal yang telah ditetapkan sebelumnya oleh perusahaan, apakah unit tiba dan diterima pelanggan tepat waktu atau telah melampaui tanggal terima yang telah ditetapkan. Dengan visualisasi, pengguna dapat mengeksplorasi, memahami, dan mengkomunikasikan data secara visual [3], serta membantu bisnis dan analis data untuk cepat dan intuitif menemukan pola menarik dan secara efektif mengkomunikasikan pengetahuan tersebut kepada bisnis dan analis data, serta pengambil keputusan [4].

\section{KAJIAN LITERATUR}

\section{A. Visual Data Mining}

Tujuan dari Visual Data Mining adalah untuk membantu pengguna merasakan data, mendeteksi ketertarikan ilmu pengetahuan, dan meningkatkan pemahaman visual terhadap data [5]. Terdapat 8 langkah visualisasi data dan metode visual data mining, kedelapan langkah tersebut dikelompokkan kedalam 3 fase, yaitu:

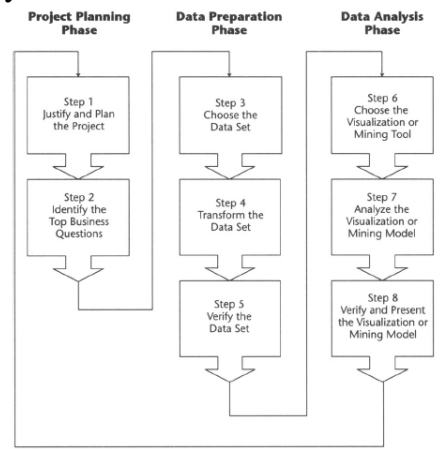

Gbr 1. Delapan Langkah Visualisasi Data dan Metode Penambangan Data Visual. 
1) Project Planning Phase, tahap ini terdiri dari justify and plan the project yang bertujuan untuk melakukan pembenaran terhadap proyek dan merencanakan proyek dengan menyediakan panduan estimasi waktu dan sumber daya yang dibutuhkan dalam pembuatan visualisasi. Fase ini membantu mendefinisikan role tim dan tanggung jawab masing-masing terhadap proyek. Identify the top business questions bertujuan untuk mengidentifikasi dan menyaring pertanyaan bisnis seputar data visualisasi.

2) Data Preparation Phase, fase ini terdiri dari choose the data set bertujuan untuk melakukan pemilihan data yang akan digunakan. Transform the data set bertujuan untuk melakukan transformasi data seperti cleansing dan filtering. Verify the data set bertujuan untuk melakukan cross check untuk dilihat kembali apakah terdapat kesalahan pada data.

3) Data Analysis Phase, fase ini terdiri dari choose the visualization or mining tool bertujuan untuk memilih tools dan model chart yang akan digunakan. Analyze the visualization or mining model bertujuan untuk menganalisis hasil dari visualisasi data yang sudah dibuat sebelumnya. Verify and present the visualization or mining model bertujuan untuk memverifikasi dan mempresentasikan hasil visualisasi kepada pengguna untuk menunjukkan informasi apa yang diperoleh dari visualisasi.

\section{B. Extract, Transform, Load (ETL)}

ETL adalah sekumpulan proses untuk mengambil dan memproses data dari satu atau banyak sumber data menjadi sumber baru [6]. ETL merupakan bagian dari data staging area, menerima data yang berasal dari berbagai macam sumber data, menjamin kualitas data, dan konsisten [7] terhadap data. Ekstraksi adalah tahap pertama untuk mendapatkan data dari berbagai macam sumber data. Ekstraksi dapat diartikan membaca dan memahami sumber data kemudian menyalin data yang dibutuhkan kedalam sistem untuk kebutuhan berikutnya, pada poin ini data disimpan kedalam gudang data (data warehouse) atau staging. Setelah data di ekstraksi kedalam sistem, tahap berikutnya adalah transformasi data seperti pembersihan data (koreksi ejaan yang salah, menghilangkan duplikasi data, atau merubah format data), dan mengabungkan beberapa sumber data. Tahap terakhir dari ETL adalah menyimpan kembali data kedalam target model dimensional, karena misi utama dari proses ETL adalah memisahkan tabel dimensi dan fakta dalam penyajian [8].

\section{Visualisasi Data}

Visualisasi data dapat didefinisikan sebagai penggunaan representasi visual untuk mengeksplorasi, memahami, dan mengkomunikasikan data [3]. Visualisasi adalah metode yang terbukti dapat mengkomunikasikan hasil temuan dari eksplorasi data yang dilakukan kepada pembuat keputusan [4]. Dengan kata lain, visualisasi data merupakan sarana penting untuk melakukan analisis data, ketika maksan sudah ditemukan dan dimengerti, makna tersebut akan dikomunikasikan kepada orang lain.

\section{Penelitian Terdahulu}

Penelitian yang dilakukan oleh Dessy Aryanti dan Johan Setiawan dengan judul Visualisasi Data Penjualan Produk dan Produksi PT Nitto Alam Indonesia Periode 2014-2018 [3] menyatakan bahwa perusahaan telah memiliki jumlah data penjualan dan produksi sebanyak 134.252 rows dimana belum pernah dilakukan analisa terhadap data penjualan dan produksi yang ada sehingga informasi yang didapat dari data tersebut belum sepenuhnya di eksplorasi. Penelitian ini menggunakan metode Visual Data Mining (VDM) dan Explaratory Data Analysis (EDA), dan pembuatan dashboard menggunakan Tableau. Hasil penelitian menunjukkan bahwa dengan metode yang digunakan dapat menghasilkan sebuah dashboard. Hasil dari eksplorasi data penjualan dan produksi dapat diketahui bahwa pola penjualan dalam lima tahun terakhir tidak memiliki pola trend, cyclic, maupun seasonal dengan puncak [enjualan tertinggi terletak pada quarter empat (Q4) ditahun 2017 sebesar $6,522 \%$. Hasil standar deviasi diketahui bahwa penjualan dan produksi ditahun 2018 cenderung semakin stabil dibanding dengan periode-periode sebelumnya. Hasil dari analisis efisiensi terhadap penjualan dan produksi diketahui bahwa AL4, BR4, dan HTB4 merupakan barang yang penualan dan produksinya tidak efisien, sedangkan MS3, TS4, dan TT3 merupakan barang yang penjualan dan produksinya efisien.hasil analisis market share diketahui bahwa pembelian oleh customer EPSON sangat jauh berbeda dengan customer lain karena EPSON memiliki total pembelian jauh lebih besar selama lima tahun terakhir (2014-2018).

Visualisasi Data Terbuka Ketahanan Pangan Provinsi Jawa Barat adalah penelitian yang dilakukan oleh Adam Mucharil Bachtiar, Dian Dharmayanti, dan Hafizha Husnaisa [9] mengenai ketersediaan pangan di wilayah Jawa Barat. Dalam penelitiannya menuturkan ketidakstabilan ketersediaan bahan pangan dapat disebabkan oleh beberapa faktor seperti siklus musim panen dan lainnya. Pemantauan aspek pangan di Jawa Barat kerap dilakukan agardapat melakukan persiapan dikemudian hari. Pemantauan dapat dilakukan melalui media data yang disediakan oleh pemerintah pusat maupun daerah. Namun data yang sudah ada kurang dimaksimalkan fungsinya karena beberapa kendala seperti sangat banyaknya data sehingga data sangat sulit dibaca dan sumber datanya terpisahpisah sehingga menyulitkan untuk mendapatkan informasi dari data yang sudah ada. Metode penelitian yang digunakan mengacu pada teknik visualisasi data umum dimana didalamnya terdapat beberapa penyesuaian yaitu pengumpulan data pra riset, analisis segmentasi pengguna informasi, analisis kebutuhan informasi, analisis sumber data, analisis pemetaan data, seleksi data, knowledge discover, visualisasi dan perbaikan, pembangunan software visualisasi, dan usability testing software. Hasil dari penelitian berupa visualisasi tabel maupun grafik yang menarik sehingga tepat dalam menyajikan data sesuai kebutuhan informasinya. 


\section{METODE PENELITIAN}

Metode penelitian yang digunakan dalam penelitian ini adalah Visual Data Mining (VDM) dan Extract, Transform, Load (ETL).

\section{A. Visual Data Mining (VDM)}

Terdapat tiga fase utama dalam metode ini, yaitu:

1) Project Planning Phase

Bertujuan melakukan pembenaran terhadap proyek dan merencanakan proyek dengan menyediakan panduan estimasi waktu dan sumber daya yang dibutuhkan dalam pembuatan visualisasi. Fase ini membantu mendefinisikan role tim dan tanggung jawab masingmasing terhadap proyek serta mengidentifikasi dan menyaring pertanyaan bisnis seputar data visualisasi.

2) Data Preparation Phase

Bertujuan untuk melakukan pemilihan data yang akan digunakan, melakukan transformasi data seperti cleansing dan filtering, kemudian melakukan cross check untuk dilihat kembali apakah terdapat kesalahan pada data.

3) Data Analysis Phase

Bertujuan untuk memilih tools dan model chart yang akan digunakan, menganalisis hasil dari visualisasi data, serta memverifikasi dan mempresentasikan hasil visualisasi kepada pengguna untuk menunjukkan informasi apa yang diperoleh dari visualisasi.

\section{B. Extract, Transform, Load (ETL)}

Tujuan dari tahap ini adalah untuk mengekstraksi data yang didapat dari berbagai macam sumber data dengan format dan struktur yang berbeda, kemudian melakukan transformasi data seperti cleansing data, menghilangkan duplikasi data, menstardarisasi format dan struktur data yang selanjutnya akan disimpan kembali kedalam staging area sehingga menjadi sebuah sumber data baru.

\section{HASIL DAN PEMBAHASAN}

Berikut adalah hasil dan pembahasan dari penelitian yang dilakukan.

\section{A. Project Planning Phase}

1) Justify and Plan The Project

Pada tahap ini dilakukan perencanaan tahap awal dengan mengumpulkan informasi-informasi yang dibutuhkan dalam pembuatan dashboard, seperti informasi sumber data, model visualisasi yang diinginkan, serta pembuatan dokumentasi perencanaan dan timeline proyek.

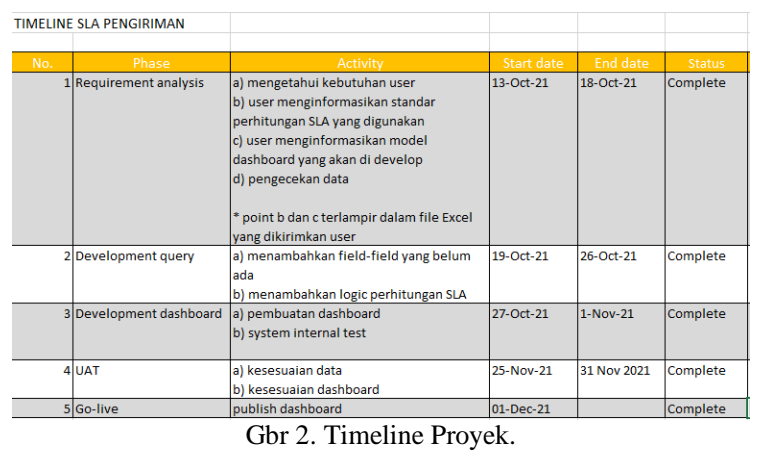

2) Identify the Top Business Question

Pada tahap ini adalah melakukan identifikasi pertanyaan-pertanyaan bisnis apa saja yang paling sering ditanyakan berdasarkan sumber data yang ada. Diskusi dilakukan dengan pihak pengguna akhir yang akan menggunakan dashboard. Permasahalan bisnis yang ingin diketahui adalah:

a) Dapat menunjukkan jumlah kategori pencapaain exceed dan within oleh vendor dan internal disetiap bulannya secara angka dan persentase.

b) Dapat menampilkan informasi data terkait kategori pencapaian exceed dan within oleh vendor dan internal.

\section{B. Data Preparation Phase}

1) Choose the Data Set

Data yang akan digunakan yaitu data yang terkait dengan data pengiriman unit customer periode JanuariDesember 2021 serta data matrix SLA yang berasal dari vendor dalam format Ms. Excel.

2) Transform the Data Set

Data set yang akan digunakan sebelumnya harus melewati tahap pembersihan data (cleansing) untuk mengurangi error dan bias pada data. Pembersihan data dilakukan dengan melakukan query untuk mengurangi data-data yang tidak dibutuhkan, merubah format tanggal, penambahan kolom kategori unit movement/non-movement.

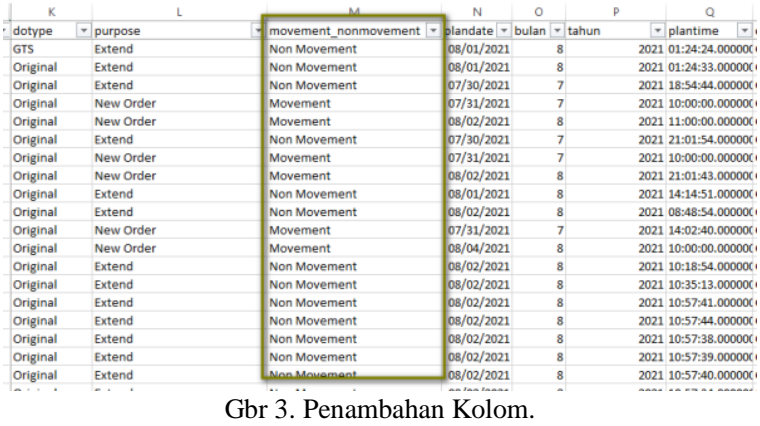

3) Verify the Data Set

Data yang sudah dilakukan transformasi, berikutnya diverifikasi dengan melakukan pengecekan kembali pada data-data apakah sudah sesuai atau belum sesuai. 
Proses verifikasi data dibantu juga oleh user agar hasilnya lebih valid.

C. Data Analysis Phase

1) Choose the Visualization or Mining Tool

Tahap ini adalah pemilihan tool untuk visualisasi dilakukan dengan menbandingkan beberapa tool lainnya serta melihat pada kelebihan dan kekurangan dari masing-masing tool. Dalam penelitian ini, tool yang digunakan dalam pembuatan visualisasi adalah Tableau.

2) Analyze the Visualization or Mining Model

Visualisasi data pada Tableau menggunakan model Text Table dimana data tersaji kedalam format tabular dan columnar layaknya Ms. Excel disesuaikan dengan permintaan user.

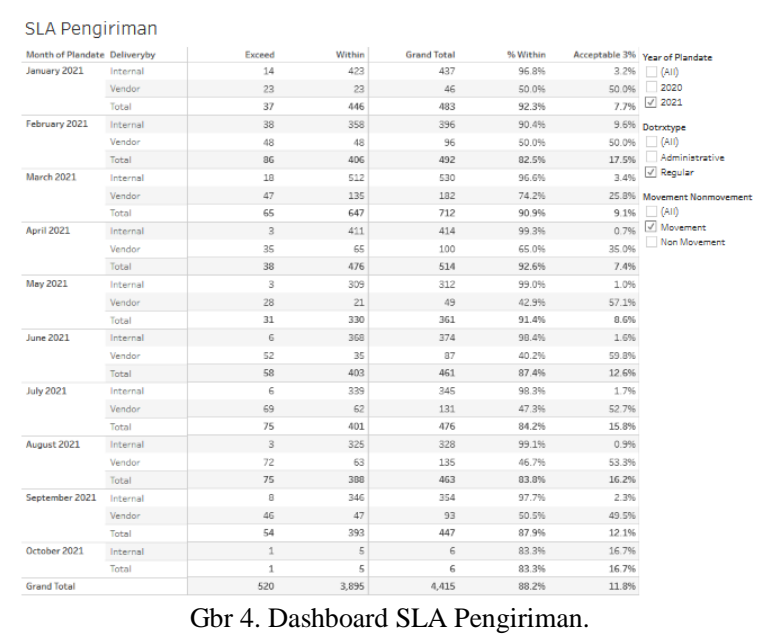

Dari gambar 4 diatas user dapat dengan mudah memahami pencapaian dari proses pengiriman yang dilakukan baik oleh vendor maupun oleh internal di setiap bulannya yang terbagi kedalam exceed dan within, dimana exceed adalah proses pengiriman yang penerimaan unit customer nya telah melewati batas tanggal penerimaan yang ditetapkan. Sedangkan within adalah proses pengiriman yang penerimaan unit customer nya kurang dari atau tepat di tanggal penerimaan yang telah ditetapkan.

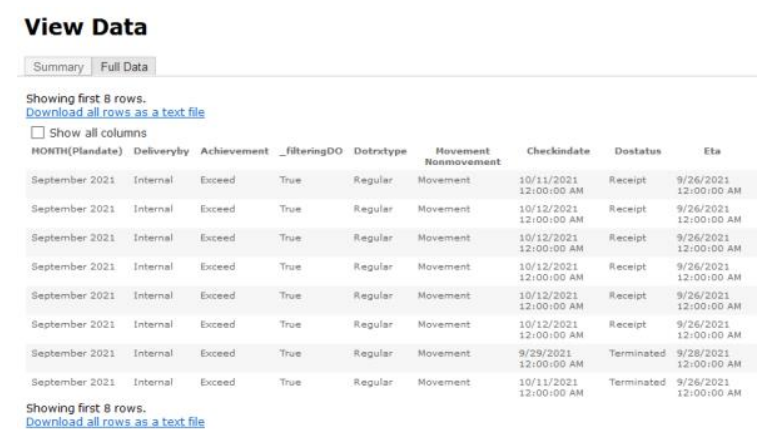

Gbr 5. View Data.
Gambar 4 menjelaskan mengenai View Data, untuk dapat melihat data lebih dalam user cukup memilih kolom-kolom yang akan ditampilkan datanya secara detail.

3) Verify and Present the Visualization or Mining Model Pada tahap ini dilakukan proses User Acceptance Test (UAT) yang di isi oleh perwakilan user, dimana hasil proses UAT menunjukkan masih ada Tempat Serah Terima yang tidak sesuai dengan alamat pengiriman sehingga menyebabkan perhitungan SLA dan hasil pencapaian proses pengiriman menjadi keliru. Hal ini disebabkan karena dalam pengisian alamat pengiriman oleh user dilapangan masih terdapat pengisian yang tidak lengkap untuk nama kota/kabupaten provinsinya, bahkan ada yang null. Namun untuk data yang digunakan dalam proses perhitungan SLA pengiriman sudah sesuai.

\section{KESIMPULAN}

Dari hasil penelitian yang telah dilakukan, dapat disimpulkan bahwa :

1) Penggunaan metode Visual Data Mining (VDM) dan Extract, Transform, Load (ETL) telah dibuktikan dengan keberhasilannya menghasilkan dashboard.

2) Hasil dari analisa data pengiriman diketahui bahwa masih terdapat kekeliruan didalam perhitungan SLA dan pencapaian yang disebabkan oleh kolom Tempat Serah Terima yang tidak sesuai dengan yang ada di alamat pengiriman.

\section{UCAPAN TERIMA KASIH}

Rasa syukur dan terima kasih diucapkan kepada semua pihak yang telah membantu, mendukung serta membimbing selama penelitian dilakukan. 


\section{REFERENSI}

[1] G. B. Arumbinang and A. Tarigan, "Konsep Dan Strategi Tata Kelola Manajemen Layanan Internet Menggunakan It Infrastructure Library," vol. 2 , no. 2 , pp. 46-52, 2018.

[2] F. Nurzaman and A. Herwanto, "Sistem Pendukung Keputusan Servis Level Agreement (SLA) Klain Asuransi Kesehatan Dengan Metode Regresi Linear dan Metode K-Means," Tek. Inform. UPI YAI, pp. 77-84, 2018.

[3] D. Aryanti and J. Setiawan, "Visualisasi Data Penjualan dan Produks PT Nitto Alam Indonesia Periode 2014-2018," Ultim. InfoSys, vol. 9, no. 2, pp. 86-91, 2019, doi: 10.31937/si.v9i2.991.

[4] T. Soukup and I. Davidson, Visual Data Mining: Techniques and Tools for Data Visualization and Mining, vol. 2002. 2002.

[5] S. J. Simoff, M. H. Bohlen, and A. (Eds. . Mazeika, Visual Data Mining Theory, Techniques and Tools for Visual Analytics. 2008.

[6] N. W. S. Saraswati and N. M. L. Martarini, "Extract Transform Loading Data Absensi Stmik Stikom Indonesia Menggunakan Pentaho," MATRIK J. Manajemen, Tek. Inform. dan Rekayasa Komput., vol. 19, no. 2, pp. 273-281, 2020, doi: 10.30812/matrik.v19i2.564.

[7] A. A. Yulianto, "Extract Transform Load (ETL) Process in Distributed Database Academic Data Warehouse," APTIKOM J. Comput. Sci. Inf. Technol., vol. 4, no. 2, pp. 61-68, 2019, doi: 10.11591/aptikom.j.csit.36.

[8] R. Kimball and M. Ross, The Data Warehouse Toolkit - The Definitive Guide to Dimensional Modelling. 2013.

[9] A. M. Bachtiar, D. Dharmayanti, and H. Husnaisa, "Visualisasi Data Terbuka Ketahanan Pangan Provinsi Jawa Barat," Komputa J. Ilm. Komput. dan Inform., vol. 6, no. 1, pp. 16-23, 2017, doi 10.34010/komputa.v6i1.2472.

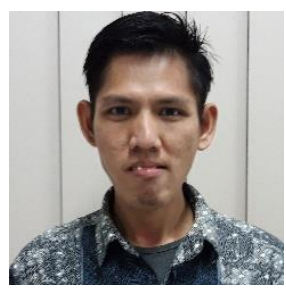

Doni Andriansyah lahir di Tangerang pada tanggal 3 Februari 1986. Lulus S1 Program Studi Sistem Informasi STMIK Nusa Mandiri pada tahun 2011 Lulus Magister Ilmu Komputer Program Pascasarjana STMIK Nusa Mandiri pada tahun 2014. Penulis buku pemrograman komputer dengan judul Sistem Informasi Pendaftaran Event Dengan PHP Untuk Panduan Skripsi. Penulis buku pemrograman komputer dengan judul Aplikasi Penerimaan Siswa Baru Online Dengan PHP, PDO, dan Bootstrap. Penulis buku pemrograman komputer dengan judul Best Practice Membangun Aplikasi Pelayanan Publik Dengan Framework Codeigniter 3. Saat ini aktif sebagai Dosen di Universitas Nusa Mandiri dan praktisi IT di sebuah perusahaan swasta. 